\title{
Does university campus experience develop motivation to lead or readiness to lead among undergraduate students? A Malaysian perspective.
}

\begin{abstract}
Do students' experiences on university campuses cultivate motivation to lead or a sense of readiness to lead that does not necessarily translate to active leadership? To address this question, a study was conducted with 369 undergraduates from Malaysia. Campus experience was more predictive of leadership readiness than motivation. Student leadership opportunities, global leadership perspective development, leadership modeling, quality of staff support, and quality of leadership training programs contributed significantly more to leadership readiness than to motivation to lead.
\end{abstract}

Keyword: Motivation to lead; Readiness to lead; Leaderships; Undergraduate students. 